\title{
Relationship between urban heat island and population density of districts in Ho Chi Minh City derived from Sentinel - 3 SLSTR data
}

\author{
Ha Thu Thi Le ${ }^{1,}$, Trung Van Nguyen ${ }^{1}$, Khoa Ngoc Nguyen ${ }^{2}$, Phuong Dang Nguyen ${ }^{2}$, \\ Tuyet Thi Vo ${ }^{3}$, Tho Giang Nguyen ${ }^{4}$, Tung Van Pham ${ }^{5}$, Dinh Van Le ${ }^{1}$ \\ ${ }^{1}$ Hanoi University of Mining and Geology, Hanoi, Vietnam \\ ${ }^{2}$ Can Tho Environment and Natural Resources Department, Can Tho, Vietnam \\ ${ }^{3}$ Ninh Kieu land registration office, Can Tho, Vietnam \\ ${ }^{4}$ Lam Dong Irrigation - traffic Construction Joint Stock Company, Lam Dong, Vietnam \\ ${ }^{5}$ Ho Chi Minh City University of Natural Resources and Environment, Ho Chi Minh City, Vietnam
}

ARTICLE INFO ABSTRACT

Article history:

Received 02nd June 2021

Revised 27hAug. 2021

Accepted 30 $0^{\text {th }}$ Sept. 2021

Keywords:

Ho Chi Minh City,

Population density,

Sentinel - 3 SLSTR,

Urban heat island.
The urban heat island occurs due to the causes of the urbanization process, of which the main reason is an increase in population density leading to the changes in artificial objects on the ground surface. Recently, using the Split - Window algorithm for two thermal infrared spectral channels with wavelengths of $11 \mu \mathrm{m}$ and $12 \mu \mathrm{m}$ to calculate the daily surface temperature with two times of day and night serves to determine the change of land surface temperature. This method is intended to improve the reliability of the results and high technical efficiency. This study uses Sentinel - 3 SLSTR data to determine urban heat island in the districts of Ho Chi Minh City compared to areas bordering the city on May 15th 2020. In addition, population density is calculated according to the results of the census in 2020. The linear relationship between the urban heat island and population density was built with the coefficient of determination $R^{2}=0.64$.

Copyright (C) 2021 Hanoi University of Mining and Geology. All rights reserved.

${ }^{*}$ Corresponding author

E - mail: lethithuha@humg.edu.vn

DOI: 10.46326/JMES.2021.62 (5).06 


\title{
Nghiên cứu mối quan hệ giữa đảo nhiệt đô thị và mật độ dân số các quận, huyện ở Thành phố Hồ Chí Minh bằng dữ liệu ảnh Sentinel - 3 SLSTR
}

\author{
Phương ${ }^{2}$, Võ Thị Tuyết ${ }^{3}$, Nguyễn Giang Thọ ${ }^{4}$, Phạm Văn Tùng 5 , Lê Văn Định ${ }^{1}$ \\ ${ }^{1}$ Khoa Trắc địa - Bản đồ và Quản lý đất đai, Trường Đại học Mỏ - Địa chất, Việt Nam \\ ${ }^{2}$ Sở Tài nguyên và Môi trường, Cần Tho, Việt Nam \\ ${ }^{3}$ Chi nhánh Văn phòng Đăng ký đất đai Quận Ninh Kiều, Việt Nam \\ ${ }^{4}$ Công ty Cổ phần Tư vấn Xây dựng Giao thông Thủy lợi Lâm Đồng, Việt Nam \\ ${ }^{5}$ Trường Đại học Tài nguyên và Môi trường TP. Hồ Chí Minh, Việt Nam
}

Lê Thị Thu Hà 1, ${ }^{*}$, Nguyễn Văn Trung ${ }^{1}$, Nguyễn Ngọc Khoa ${ }^{2}$, Nguyễn Đăng

THÔNG TIN BÀI BÁO T TÓM TẮT

Quá trình:

Nhận bài 02/6/2021

Sửa xong $27 / 8 / 2021$

Chấp nhận đăng 30/9/2021

Tù̀ khóa:

Đảo nhiệt đô thị,

Nhiệt độ bề mặt,

Sentinel - 3 SLSTR,

Thành phố Hồ Chí Minh.
Đảo nhiệt đô thị xảy ra do các nguyên nhân của quá trình đô thị hóa, trong đó nguyên nhân chính do sự tăng mật độ dân số dẫn đến các thay đổi các đối tượng nhân tạo trên bề mặt đất. Gần đây, việc sử dụng thuật toán Split Window đối với hai kênh phổ hồng ngoại nhiêt có bước sóng 11 um và $12 \mu \mathrm{m}$ để tính toán nhiêt độ bề măt hàng ngày với hai thò̀i điểm ngày và đêm phuc vụ xác định sự thay đổi nhiệt độ bề mặt đất mang lại hiệu quả cao về mặt kỹ thuật. Nghiên cúu này sử dụng dũ liệu Sentinel - 3 SLSTR để xác định sự đảo nhiệt đồ thị ở các quận và huyện thuộc Thành phố Hồ Chí Minh ngày 15/05/2020 so với các khu vực giáp thành phố. Bên canh đó, mật độ dân số được tính toán theo kết quả điều tra dân số vào đầu năm 2020. Mối quan hệ tuyến tính thuận giữa giá trị đảo nhiệt đô thị và mật độ dân số được xây dựng với hệ số xác định $R^{2}=0,64$.

CC 2021 Trường Đại học Mỏ - Địa chất. Tất cả các quyền được bảo đảm.

\section{Mở đầu}

Phương pháp sử dụng kênh phổ hồng ngoại nhiệt của các bộ cảm đặt trên các vệ tinh để cung cấp nhiệt độ bề mặt đất mang lại hiệu quả rõ rệt đối với phạm vi áp dụng trong không gian rộng

*Tác giả liên hệ

E-mail: lethithuha@humg.edu.vn DOI: 10.46326/JMES.2021.62 (5).06 và quan trắc đa thời gian nhằm cung cấp các thay đổi về nhiệt độ bề mặt nhanh chóng (Claudia và Stefan, 2013). Các tiến bộ về phương pháp xác định nhiệt độ bề mặt được thể hiện qua việc sử dụng hai kênh phổ hồng ngoại nhiệt có bước sóng $11 \mu \mathrm{m}$ và $12 \mu \mathrm{m}$ để áp dụng thuật toán Split - Window nhằm nâng cao độ tin cậy thay vì sử dụng một kênh hồng ngoại nhiệt đơn (Zheng Y. và nnk., 2019).

Vệ tinh Seitinel - 3 mang theo các bộ cảm biến để thực hiện đa nhiệm vụ, trong đó bộ cảm 
biến Sentinel - 3 Sea and Land Surface Temperature Radiometer (SLSTR) với 11 kênh phổ có phần thực hiện cung cấp nhiệt độ bề mặt đất và biển. Để thực hiện công việc này, ngoài hai kênh hồng ngoại nhiệt cần phải sử dụng các kênh phổ và các thông số khác để tính toán nhiệt độ bề mặt bao gồm: góc chụp, tỷ lệ thực phủ, kiểu thực phủ, lượng nước trong khí quyển và trong các lớp phủ bề mặt (Jiajia Y. và nnk., 2020). Thông thường các dữ liệu Sentinel - 3 SLSTR được cung cấp vào ban ngày với độ phân giải không gian $1 \mathrm{~km}$ được sử dụng để xác định sự đảo nhiệt đô thị. Thực chất của sự đảo nhiệt đô thị là sự chênh lệch nhiệt độ ở vùng trung tâm của đô thị và phụ cận so với nền nhiệt chung của các khu vực xung quanh. Do vậy, giá trị của bản đồ đảo nhiệt đô thị chính là hiệu giá trị nhiệt độ bề mặt ở các vùng ranh giới hành chính trung tâm với giá trị nhiệt độ ở vùng nền không phải khu vực đô thị ở xung quanh (Sobrino và Irakulis, 2020).

Rất nhiều nghiên cứu đã chỉ ra rằng hiện tượng đảo nhiệt đô thị là do ảnh hưởng bởi một loạt các yếu tố như: sự trao đổi bức xạ (bao gồm bức xạ mặt trời và bức xạ trái đất), hoạt động của gió, sự suy giảm mật độ và loại cây xanh trồng trong đô thị, sự gia tăng bề mặt không thấm nước, sự gia tăng mật độ dân số và những hoạt động gây phát thải nhiệt của con người (Hassan R. và nnk., 2012; Ha Thu Thi Le và nnk., 2018; Zhang Z. và nnk., 2008; Lê Thị Thu Hà và nnk., 2020). Trong đó, nguyên nhân chính gây ra hiện tượng đảo nhiệt ở các đô thị là do sự gia tăng mật độ dân số trong một đơn vị hành chính cụ thể (Brian và Michael, 2001; Le Thi Thu Ha và nnk., 2021). Điều này kéo theo sự biến động các lớp phủ bề mặt với nhiều đối tượng lớp phủ nhân tạo mới tạo nên cấu trúc và hình thái đô thị mới gây nên hiện tượng gia tăng nhiệt độ bề mặt. Các nghiên cứu trước đã chỉ ra sự chênh lệch nhiệt độ bề mặt ở các khu vực trung tâm đô thị có thể chênh lệch tăng từ $5 \div 10^{0}$ so với khu vực xung quanh tùy vào đặc điểm cấu trúc và hình thái của khu vực đó (Brian và Michael, 2001; Lê Thị Thu Hà và nnk., 2020).

Nghiên cứu này tập trung vào: (1) xác định sự đảo nhiệt ở các quận và huyện ở Thành phố Hồ Chí Minh bằng cách tính toán sự chênh lệch nhiệt độ so với nền nhiệt độ bề mặt các khu vực xung quanh; (2) xác định mối quan hệ giữa đảo nhiệt đô thị và mật độ dân số cho từng quận, huyện Thành phố Hồ Chí Minh dựa vào phương pháp hồi qui tuyến tính.

\section{Khu vực nghiên cứu và dữ liệu sử dụng}

Thành phố Hồ Chí Minh là thành phố lớn nhất cả nước với diện tích 2.095,239 km² bao gồm 19 quận và 5 huyện. Vị trí địa lý của khu vực nghiên cứu nằm trong khoảng từ $10^{0} 20^{\prime} \div 11^{0} 10^{\prime}$ vĩ độ Bắc và từ $106^{0} 20^{\prime} \div 107^{0} 00^{\prime}$ kinh độ Đông (Hình 1). Trong năm, thành phố có 2 mùa mưa và mùa khô rõ rệt. Mùa mưa được bắt đầu từ tháng 5 tới tháng 11 (khí hậu nóng ẩm, nhiệt độ cao mưa nhiều), còn mùa khô từ tháng 12 tới tháng 4 năm sau (khí hậu khô, nhiệt độ cao và mưa ít). Trung bình, Thành phố Hồ Chí Minh có $160 \div 270$ giờ nắng/tháng, nhiệt độ trung bình $27{ }^{\circ} \mathrm{C}$, cao nhất lên tới $40^{\circ} \mathrm{C}$, thấp nhất xuống $13,8{ }^{\circ} \mathrm{C}$. Hàng năm, Thành phố Hồ Chí Minh có 330 ngày nhiệt độ trung bình $25^{\circ} \mathrm{C} \div 28^{\circ} \mathrm{C}$ (Hochiminhcity.gov.vn, 2011).

Theo kết quả điều tra dân số chính thức vào thời điểm ngày 01 tháng 4 năm 2019 thì dân số thành phố là 8.993 .082 người và cũng là nơi có mật độ dân số cao nhất Việt Nam (Tổng cục thống kê, 2019). Tuy nhiên, nếu tính những người cư trú không đăng ký hộ khẩu thì dân số thực tế của thành phố này năm 2017 là hơn 13 triệu người (Thảo Nguyên, 2017). Như vậy, Thành phố Hồ Chí Minh đang chịu áp lực rất lớn về dân số, tác động lên toàn bộ hệ thống, trong đó có môi trường sống.

Dữ liệu sử dụng trong nghiên cứu là ảnh Sentinel - 3 SLSTR mức độ xử lý 2 với hệ tọa độ UTM, WGS84 - 48N. Ảnh sau khi được nắn chỉnh hình học được cắt theo ranh giới hành chính Thành phố Hồ Chí Minh và biểu thị dưới giá trị nhiệt độ $\left({ }^{\circ} \mathrm{C}\right)$ với thang chú giải màu sắc như trong Hình 1.

Dũ liệu Sentinel - 3 SLSTR gồm 11 kênh đa phổ như Bảng 1. Các kênh phổ dải sóng nhìn thấy và cận hồng ngoại (VNIR) và hồng ngoại ngắn (SWIR) với độ phân giải $500 \mathrm{~m}$ được sử dụng để tính tỷ lệ thực phủ, kiểu thực phủ, lượng nước trong khí quyển phục vụ xác định các hệ số $a, b$ và $c$ trong công thức 1 . Các kênh phổ Thermal InfraRed (TIR) với độ phân giải không gian $1 \mathrm{~km}$ sử dụng để tính $T_{11}$ và $T_{12}$ trong công thức 1. 
Bản đồ nhiệt độ bề mặt TP. Hồ Chí Minh ngày15-05-2020

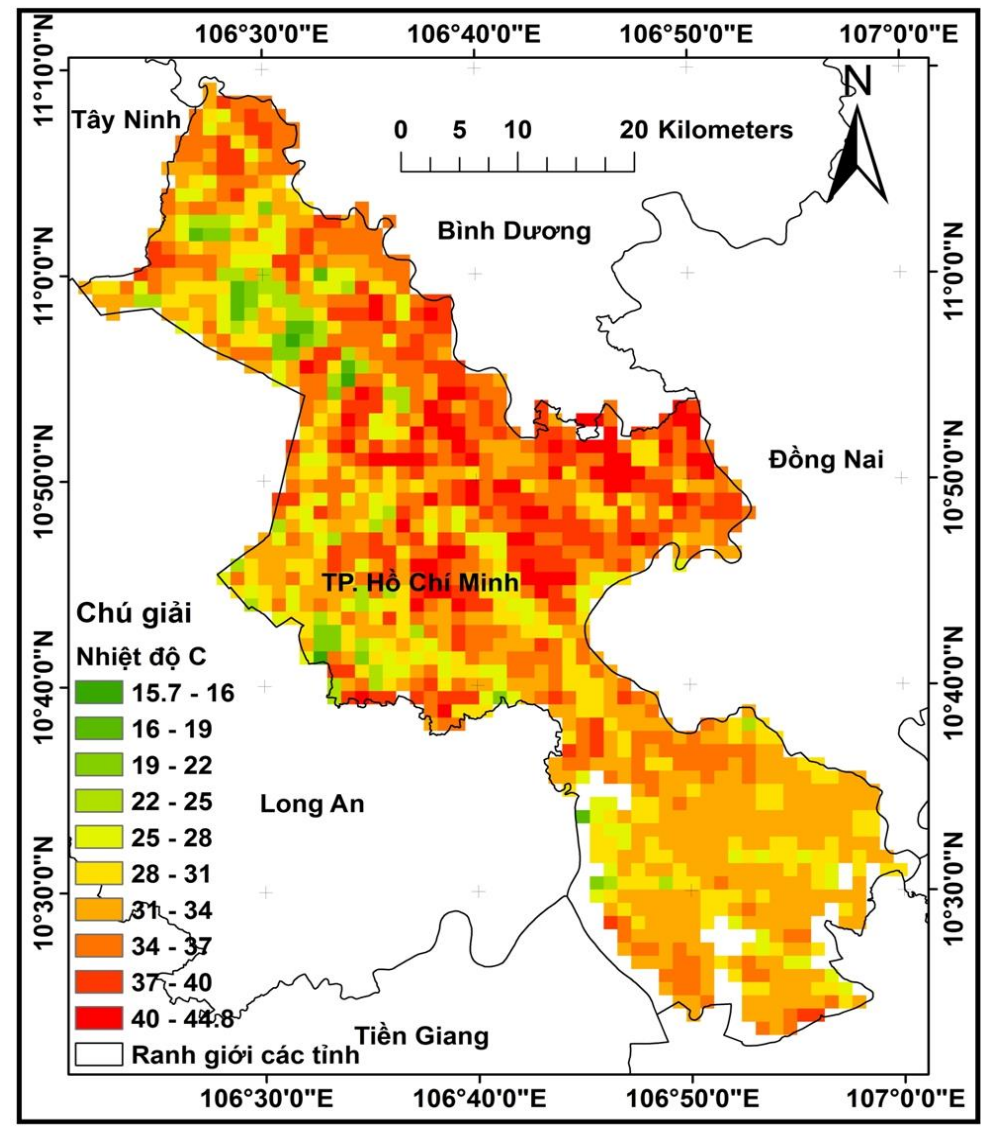

Hình 1. Bản đồ phân bố nhiệt độ bề mặt khu vực Thành phố Hồ Chí Minh ngày 15 - 5 - 2020.

Bảng 1. Các kênh phổ của Sentinel - 3 SLSTR (eesa, 2021).

\begin{tabular}{|c|c|c|c|c|c|c|}
\hline Kênh & $\begin{array}{l}\text { Bước sóng } \\
\text { trung bình, } \\
\text { (nm) }\end{array}$ & $\begin{array}{c}\text { Độ rộng, } \\
\text { (nm) }\end{array}$ & Chức năng & \multicolumn{2}{|c|}{ Chú thích } & $\begin{array}{l}\text { Độ phân } \\
\text { giải }(\mathrm{m})\end{array}$ \\
\hline S1 & 554,27 & 19,26 & & \multirow{3}{*}{$\begin{array}{c}\text { Nhìn thấy và } \\
\text { cận hồng } \\
\text { ngoại }\end{array}$} & \multirow{6}{*}{$\begin{array}{c}\text { Các kênh phổ } \\
\text { phản xạ năng } \\
\text { lượng mặt } \\
\text { trời }\end{array}$} & \multirow{6}{*}{500} \\
\hline S2 & 659,47 & 19,25 & Chỉ số NDVI, giám sát thực vật, sol khí & & & \\
\hline S3 & 868,00 & 20,60 & Chỉ số NDVI, xác định mây, hiệu chỉnh pixel & & & \\
\hline S4 & 1374,80 & 20,80 & Xác định mây che phủ mặt đất & \multirow{3}{*}{$\begin{array}{l}\text { Hồng ngoại } \\
\text { ngắn }\end{array}$} & & \\
\hline S5 & 1613,40 & 60,68 & Giám sát bang, tuyết và thực vật & & & \\
\hline S6 & 2255,70 & 50,15 & Trạng thái thực vật và loại bỏ mây & & & \\
\hline S7 & 3742,00 & 398,00 & Nhiệt độ bề mặt đất và biển, hoạt động cháy & \multirow{3}{*}{\multicolumn{2}{|c|}{$\begin{array}{c}\text { Các kênh phổ hồng ngoại } \\
\text { nhiệt môi trường xung } \\
\text { quanh }\end{array}$}} & \multirow{5}{*}{1000} \\
\hline S8 & 10854,00 & 776,00 & Nhiệt độ bề mặt đất và biển, hoạt động cháy & & & \\
\hline S9 & 12022,50 & 905,00 & Nhiệt độ bề mặt đất và biển & & & \\
\hline F1 & 3742,00 & 398,00 & Hoạt động cháy & \multirow{2}{*}{\multicolumn{2}{|c|}{$\begin{array}{l}\text { Các kênh hồng ngoại nhiệt } \\
\text { phát xạ phổ do cháy }\end{array}$}} & \\
\hline F2 & 10854,00 & 776,00 & Hoạt động cháy & & & \\
\hline
\end{tabular}

Mục đích của các kênh hồng ngoại nhiệt S7, S8 và S9 không những xác định nhiệt độ bề mặt mà còn sử dụng chức năng để xác định các hoạt động do sự cháy (nhiệt độ bề mặt tăng nhanh bất thường) thông qua các kênh $\mathrm{F} 1$ và $\mathrm{F} 2$ có trên bộ cảm biến (Bảng 1).

\section{Phương pháp nghiên cứu}

\subsection{Qui trình các bước tiến hành thực nghiệm}

Hình 2 mô tả chi tiết các bước thực nghiệm của nghiên cứu này, dữ liệu đầu vào của quy 
trình là ảnh Sentinel - 3 SLSTR và dữ liệu mật độ dân số năm 2020 của Thành phố Hồ Chí Minh. Sau khi tính toán nhiệt độ bề mặt và đảo nhiệt các quận, huyện từ ảnh Sentinel - 3 SLSTR, nghiên cứu này đã sử dụng phương pháp Hồi qui tuyến tính để xác định mối quan hệ giữa hiện tượng đảo nhiệt và mật độ dân số đô thị của các quận, huyện ở Thành phố Hồ Chí Minh.

\subsection{Tính toán nhiệt độ bề mặt tù̀ các kênh ảnh Sentinel - 3 SLSTR}

Nghiên cứu của (Prata, 1994; NILU, 2012) đã tiến hành đưa ra công thức tính nhiệt độ bề mặt theo thuật toán Split - Window đối với hai kênh phổ hồng ngoại nhiệt có bước sóng $11 \mu \mathrm{m}$ và $12 \mu \mathrm{m}$ như sau:

$$
\begin{aligned}
L S T=a_{f, i, p w}+ & b_{f, i}\left(T_{11}-T_{12}\right)^{n} \\
& +\left(b_{f, i}+c_{f, i}\right) T_{12}
\end{aligned}
$$

Trong đó: $L S T$ - nhiệt độ bề mặt; $n=$ $\frac{1}{\cos (\theta / m)} ; \theta$ - góc chụp của vệ tinh; $m$ - thông số điều khiển biến phụ thuộc vào góc chụp; $f$ - tỷ lệ thực phủ; $i$ - kiểu thực phủ (biome); $p w$ - lượng nước trong khí quyển; $T_{11}$ và $T_{12}$ - đơn vị đo nhiệt độ độ sáng trong kênh phổ SLSTR $11 \mu \mathrm{m}$ và $12 \mu \mathrm{m}$; đơn vị độ Kelvin.

Các thông số trong công thức 1 được tính cụ thể như sau:

$$
\begin{gathered}
a_{f, i, p w}=d[\sec \theta-1] p w+f a_{v, i} \\
+(1-f) a_{s, i} \\
b_{f, i}=f b_{v, i}+(1-f) b_{s, i} \\
c_{f, i}=f c_{v, i}+(1-f) b_{s, i} \\
(0 \leq f \leq 1) .
\end{gathered}
$$

Một tập hợp các hệ số được áp dụng cho từng pixel tùy thuộc vào kiểu thực phủ $i$, tỷ lệ thực vật $f$ và lượng nước $p w$, nhưng cũng phụ thuộc vào các giá trị phần trăm của thảm thực vật $(v)$ và đất trống $(s)$. Các thông số $a_{v, i} ; a_{s, i} ; b_{v, i}$; $b_{s, i} ;$ và $c_{v, i} ; c_{s, i}$ được định nghĩa là các hệ số truy xuất cơ sở. Tham số $d$ - biến kiểm soát sự phụ thuộc của hơi nước vào góc chụp và độc lập với các thông số bề mặt và khí quyển.

Sự kết hợp của hai kênh hồng ngoại nhiệt theo phương pháp (split - window) ở trên và việc tính toán hệ số thông qua các phép tính truyền bức xạ về bản chất cung cấp một hiệu chỉnh khí quyển hiệu quả trong điều kiện bầu trời quang đãng. Sự phụ thuộc hơi nước là rõ ràng trong thuật ngữ $p w$ trên toàn dải, nhưng mặt khác được mong đợi sẽ được bao hàm đầy đủ thông qua sự phù hợp hồi quy thống kê của các hệ số truy xuất cơ sở. Điều quan trọng nhất là quá trình mô phỏng nhiệt độ độ sáng và cụ thể là mô hình truyền bức xạ, có khả năng tính toán chính xác quá trình truyền trong khí quyển. Vì bầu không khí cũng có thể thay đổi đáng kể từ tháng này sang tháng khác, nên các hệ số được thực hiện hàng tháng (NILU, 2012).

\subsection{Phương pháp xác định sự đảo nhiệt đô thị}

Từ kết quả nhiệt độ bề mặt tính cho từng pixel, nhiệt độ bề mặt trung bình của các quận, huyện được xác định. Bên cạnh đó, nhiệt độ nền trung bình của các khu vực xung quanh cũng được tính toán. Chênh lệch nhiệt độ bề mặt trung bình các quận, huyện ở thành phố so với nhiệt độ bề mặt trung bình nền xung quanh được tính bằng hiệu số giữa nhiệt độ bề mặt trung bình của hai vùng này (Serco Italia SPA, 2018).

Sự đảo nhiệt đô thị được xác định sử dụng các ngày 13,14 và 15 tháng 5 năm 2020 để loại trừ các sai số ở một thời điểm nhằm nâng cao độ tin cậy của phương pháp. Các bước thực hiện tính toán nhiệt độ bề mặt và đảo nhiệt đô thị được tiến hành trên phần mềm SNAP 8.0 và được vector hóa để chuyển sang phần mềm ArcGIS 10.3 để biên tập bản đồ đảo nhiệt đô thị cho các quận, huyện.

\subsection{Phương pháp hồi qui tuyến tính xác định mối quan hệ giữa đảo nhiệt đô thị và mật độ dân số}

Mật độ dân số đối với từng quận, huyện được tính bằng tỷ số giữa số dân (theo niên giám thống kê gần nhất) và diện tích theo đơn vị $\mathrm{km}^{2}$. Đơn vị của mật độ dân số là số người $/ \mathrm{km}^{2}$ được thể hiện trong bảng thống kê và được biểu thị trực tiếp trên bản đồ theo đơn vị hành chính.

Thành phố Hồ Chí Minh có 19 quận và 5 huyện. Như vậy, hàm hồi qui tuyến tính được xây dựng từ 24 điểm được lấy từ kết quả đảo nhiệt đô thị ở các quận, huyện và mật độ dân số tương ứng. Hệ số xác định $\left(\mathrm{R}^{2}\right)$ đối với hàm hồi 
qui tuyến tính được xác định để biểu thị mức độ hồi qui của mối quan hệ giữa sự đảo nhiệt đô thị và mật độ dân số (McClave và Sincich, 2000).

\section{Kết quả và thảo luận}

\subsection{Bản đồ đảo nhiệt đô thị xác định tù̀ ảnh Sentinel - 3 SLSTR (Hình 3)}

Hiện tượng đảo nhiệt đô thị xảy ra mạnh nhất ở các Quận $3,4,10$ và 11 , các quận này nằm ở trung tâm của Thành phố Hồ Chí Minh. Các Quận 1, 5, 12, Phú Nhuận, Bình Thạnh, Thủ Đức và Gò Vấp có diễn ra hiện tượng đảo nhiệt tương đối mạnh, giá trị từ $6 \div 8{ }^{\circ} \mathrm{C}$. Các quận khác càng ra xa trung tâm có sự đảo nhiệt càng giảm, trong đó có 3 khu vực huyện Cần Giờ, huyện Củ Chi và huyện Bình Chánh là 3 khu vực cách xa trung tâm thành phố, có diện tích lớn và mật độ dân số ít, nên hiện tượng đảo nhiệt đô thị xảy ra trên 3 khu vực này rất nhỏ.

\subsection{Bản đồ đảo nhiêt đô thì và mât độ dân số các quận trung tâm ở Thành phố Hồ Chí Minh (Hình 4)}

Mật độ dân số theo từng quận, huyện (người $/ \mathrm{km}^{2}$ ) được ký hiệu dạng điểm theo thang qui ước tương ứng mức độ mật độ dân số và hiển thị lên bản đồ đảo nhiệt đô thị đối theo đơn vị hành chính các quận ở trung tâm Thành phố Hồ Chí Minh như Hình 4.

Kết quả trong Hình 4 cho thấy các quận ở trung tâm có diện tích nhỏ tương ứng với mật độ dân số cao là những nơi xảy ra hiện tượng đảo nhiệt đô thị lớn nhất. Ngược lại các quận, huyện càng ra xa trung tâm diện tích lớn dần có sự giảm dần mật độ dân số tương ứng với sự giảm hiện tượng đảo nhiệt đô thị so với các quận ở trung tâm thành phố.

Như vậy, các quận có mật độ dân số cao thường có diện tích nhỏ và quy mô dân số lớn nên nhu cầu xây dựng các đối tượng nhân tạo để phục vụ các nhu cầu sinh hoạt và phát triển kinh tế - xã hội cũng cao. Đây là nguyên nhân chính dẫn đến sự biến động các đối tượng bề mặt về cấu trúc và hình thái của đô thị trong quá trình xây dựng và phát triển.

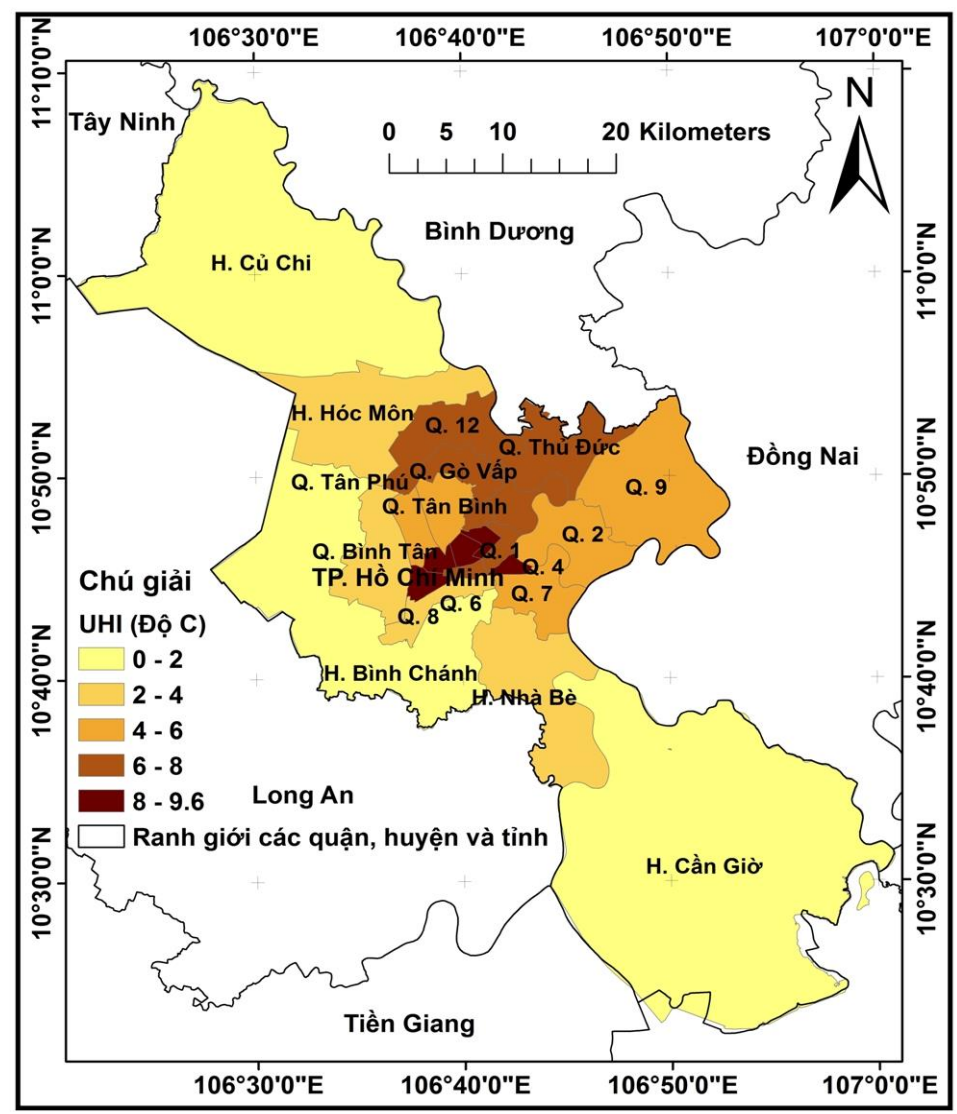

Hình 3. Bản đồ đảo nhiệt đô thị các quận, huyện ở Thành phố Hồ Chí Minh. 


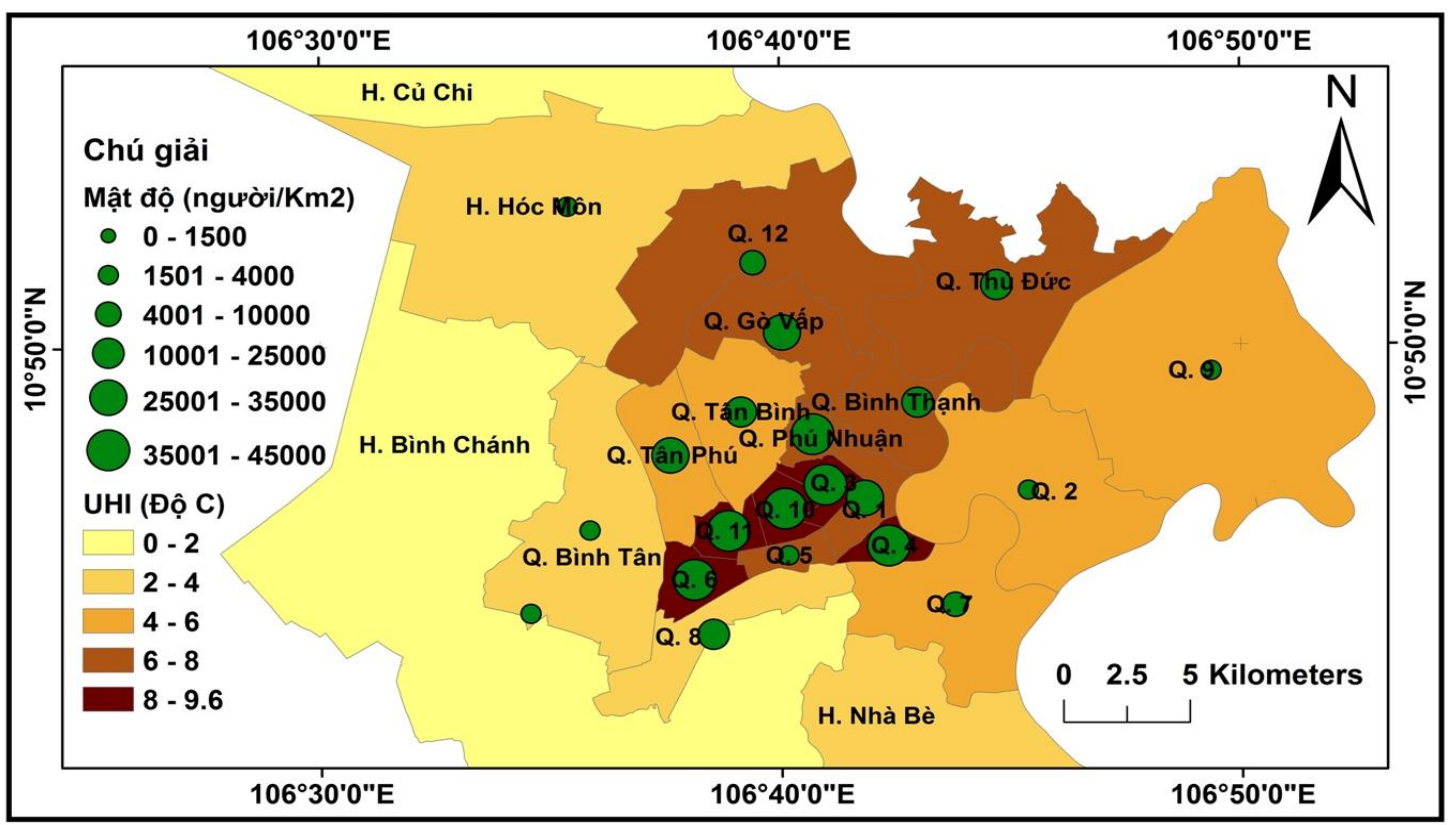

Hình 4. Bản đồ mật độ dân số và đảo nhiệt đô thị các quận, huyện ở Thành phố Hồ Chí Minh.

\subsection{Hồi qui tuyến tính mối quan hệ giũ̃a sự đảo nhiệt đô thị các quận, huyện ở Thành phố Hồ Chí Minh}

Kết quả hồi qui tuyến tính từ Bảng 2 nhận được hàm hồi qui ở phía trên của Hình 5 và được biểu diễn bởi hàm quan hệ tuyến tính giữa mật độ dân số và sự đảo nhiệt trong từng quận, huyện thuộc Thành phố Hồ Chí Minh. Kết quả hàm hồi qui có hệ số xác định $\mathrm{R}^{2}=0,64$, điều có cho thấy có mối quan hệ giữa hiện tượng đảo



Hình 5. Hồi qui tuyến tính sự đảo nhiệt đô thị và mật độ dân số các quận, huyện ở Thành phố Hồ Chí Minh. nhiệt đô thị và mật độ dân số của các quận, huyện ở Thành phố Hồ Chí Minh.

Bảng 2. Dũ liệu về đảo nhiệt đô thị và mật độ dân số ở Thành phố Hồ Chí Minh (Tổng cục Thống kê, 2019).

\begin{tabular}{|c|c|c|c|}
\hline TT & Tên quận, huyện & $\begin{array}{c}\text { Đảo nhiệt } \\
\text { đđộ C) }\end{array}$ & $\begin{array}{c}\text { Mật độ dân số } \\
\text { (người) }\end{array}$ \\
\hline 1 & H. Bình Chánh & 1,7 & 2338 \\
\hline 2 & H. Cần Giờ & 2,0 & 106 \\
\hline 3 & H. Củ Chi & 2,0 & 927 \\
\hline 4 & H. Hóc Môn & 3,9 & 3876 \\
\hline 5 & H. Nhà Bè & 3,3 & 1392 \\
\hline 6 & Q. 1 & 7,7 & 25179 \\
\hline 7 & Q.10 & 8,3 & 41012 \\
\hline 8 & Q.11 & 9,1 & 44784 \\
\hline 9 & Q.12 & 6,8 & 9664 \\
\hline 10 & Q. 2 & 4,9 & 2958 \\
\hline 11 & Q. 3 & 8,2 & 38494 \\
\hline 12 & Q.4 & 9,6 & 44564 \\
\hline 13 & Q. 5 & 6,8 & 3623 \\
\hline 14 & Q. 6 & 9,2 & 35965 \\
\hline 15 & Q. 7 & 4,3 & 8689 \\
\hline 16 & Q. 8 & 3,9 & 22499 \\
\hline 17 & Q. 9 & 5,7 & 2561 \\
\hline 18 & Q. Bình Thạnh & 6,9 & 23484 \\
\hline 19 & Q. Bình Tân & 2,7 & 2836 \\
\hline 20 & Q. Gò Vấp & 7,3 & 32186 \\
\hline 21 & Q. Phú Nhuận & 6,8 & 37616 \\
\hline 22 & Q. Thủ Đức & 7,3 & 10986 \\
\hline 23 & Q. Tân Bình & 4,7 & 20639 \\
\hline 24 & Q. Tân Phú & 5,7 & 28850 \\
\hline
\end{tabular}




\section{Kết luận}

Nghiên cứu này đã thử nghiệm phương pháp xác định đảo nhiệt đô thị từ dư liệu Sentinel - 3 SLSTR. Các dữ liệu nhiệt độ bề mặt có sử dụng hai kênh hồng ngoại nhiệt có bước sóng $11 \mu \mathrm{m}$ và $12 \mu \mathrm{m}$ với phương pháp Split Window cung cấp nhiệt độ bề mặt ít chịu ảnh hưởng của lượng nước trong khí quyển cũng như các thành phần thực vật và đất trống trên bề mặt.

Các dữ liệu về mật độ dân số của từng quận, huyện cũng được biểu thị trên cùng không gian bản đồ đảo nhiệt đô thị ở Thành phố Hồ Chí Minh. Bên cạnh đó, các kết quả đảo nhiệt và mật độ dân số cho các quận, huyện được thống kê theo bảng và xác định hàm hồi qui tuyến tính mối quan hệ của hai yếu tố này. Hệ số xác định của hàm hồi quy tuyến tính nhận được là $\mathrm{R}^{2}=0,64$ cho thấy có mối quan hệ giữa sự đảo nhiệt và mật độ dân số ở các quận, huyện thuộc Thành phố Hồ Chí Minh.

\section{Đóng góp của các tác giả}

Lê Thị Thu Hà, Nguyễn Văn Trung - lên ý tưởng, xây dựng đề cương, xây dựng quy trình nghiên cứu, đọc bản thảo bài báo và cho các ý kiến góp ý; Nguyễn Ngọc Khoa, Võ Thị Tuyết, Nguyễn Giang Thọ - thu thập số liệu, triển khai thực nghiệm; Nguyễn Đăng Phương, Phạm Văn Tùng, Lê Văn Định - xử lý số liệu và viết bản thảo.

\section{Tài liệu tham khảo}

Brian S. Jr., Michael O. R., (2001). Urban Form and Thermal Efficiency: How the Design of Cities Influences the Urban Heat Island Effect. Journal of the American Planning Association, 67(2), $186-198$.

Claudia, K., Stefan, D. (2013). Thermal Infrared Remote Sensing: Sensors, Methods, Applications. Remote Sensing and Digital Image Processing.

Ha Thu Thi Le, Trung Van Nguyen, Lan Thi Pham, Le Thi Le, Huong Thuy Duong, Long Huu Nguyen. (2018). Impact of urbanization on land surface temperature using remote sensing and GIS: A case of Tay Ho district, Hanoi city, Vietnam. Journal of Mining and
Earth Sciences, 59(6), 64-73.

Hassan Rhinane, Atika Hilali, Hicham Bahi, Aziza Berrada. (2012). Contribution of Landsat TM Data for the Detection of Urban Heat Islands Areas Case of Casablanca. Journal of Geographic Information System, $4(1)$.

Jiajia Y., Ji Z., Frank - Michael G., Zhiyong L., Jin M., Ren L. (2020). Investigation and validation of algorithms for estimating land surface temperature from Sentinel - 3 SLSTR data. International Journal of Applied Earth Observation and Geoinformation, 91, 14.

"Khí hậu, thời tiết". Website Thành phố Hồ Chí Minh. Lưu trữ bản gốc ngày 25 tháng 5 năm 2009. Truy cập ngày 22 tháng 5 năm 2014. https://hochiminhcity.gov.vn/-/khi-hau-thoitiet.

Le Thi Thu Ha, Nguyen Van Trung, Pham Thi Lan, Tong Thi Huyen Ai, La Phu Hien, (2021). Impacts of Urban Land Cover Change on Land Surface Temperature Distribution in Ho Chi Minh City, Vietnam. Journal of the Korean Society of Surveying, Geodesy, Photogrammetry and Cartography, 39(2), 13-21.

Lê Thị Thu Hà, Đoàn Đắc Nhất, Huỳnh Thị Lam, Nguyễn Thị Thanh Thúy, Nguyễn Thị Ngọc Hiệp, Lưu Thị Thanh Thủy, Vo Thị Cong Chınh, Lê Thanh Nghị. (2020). Đánh gia vai trò của cơ cấu lớp phủ bề mặt đô thị trong việc giảm hiệu ứng đảo nhiệt đô thị áp dụng cho khu vực Thành phố Hồ Chí Minh, Việt Nam. Tạp chí Khoa học kỹ thuật Mỏ - Địa chất, 61 (2), 76-85.

McClave, J. T., and Sincich, T., (2000). Simple linear regression in Statistics. 8th edition, Prentice Hall, USA, 505 - 557

Prata, A. J. (1994). Land surface temperature determination from satellites. Advances in space research, 14, 15 - 26.

Serco Italia SPA. (2018). Urban heat island with Sentinel - 3. (version 1.1). Retrieved from RUS Lectures at https://ruscopernicus.eu/ portal/ the - rus - library/learn - by - yourself/

Sobrino, J. A., Irakulis, I. A. (2020). Methodology for 
Comparing the Surface Urban Heat Island in Selected Urban Agglomerations Around the World from Sentinel - 3 SLSTR Data. Remote Sensing, 12, 29.

Thảo Nguyên, (2017). Chuyên trang Tri thức trẻ. http://ttvn.toquoc.vn/kinh-doanh/chu-tichnguyen-thanh-phong-du-bao-dan-so-tp-ho-chi -minh-den-nam-2025-la-10-trieu-nguoi-nhung -nay-da-dat-13-trieu-nguoi5201717811412441.htm.

The European Space Agency. (2021). Sentinel-3 SLSTR resolutions.

Tổng cục Thống kê. (2019). Kết quả tổng điều tra dân số và nhà ở thời điểm 0 giờ ngày 1.4.2019.

Theo Chỉ thị số 44/CT - TTg của Thủ tướng Chính
University of Leicester/NILU, (2012). SLSTR ATBD land surface temperature. Sentinel - 3 optical products and algorithm definition, 55 pages.

Zhang, Z., Ji, M., Shu, J., Deng, Z., Wu, Y. (2008). Surface Urban Heat Island in Shanghai, China: Examining the Relationship between Land Surface Temperature and Impervious Surface Fractions Derived from Landsat ETM+ imagery. Int. Arch. Photogramm. Remote Sens. Spat. Inf. Sci., 37, 601-606.

Zheng, Y., Ren, H., Guo, J., Ghent, D., Tansey, K., Hu, X., Nie, J., Chen, S. (2019). Land Surface Temperature Retrieval from Sentinel - 3A Sea and Land Surface Temperature Radiometer, Using a Split - Window Algorithm. Remote Sensing, 11, 650. 